Available online on 15.10 .2018 at http://jddtonline.info

Journal of Drug Delivery and Therapeutics

Open Access to Pharmaceutical and Medical Research

(c) 2011-18, publisher and licensee JDDT, This is an Open Access article which permits unrestricted non-commercial use, provided the original work is properly cited

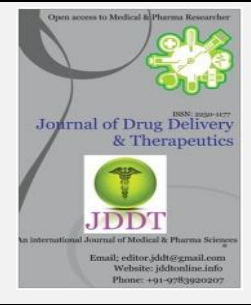

\title{
FORMULATION, CHARACTERIZATION AND EVALUATION OF ANTI-INFLAMMATORY AND ANTI-ANGIOGENIC ACTIVITIES OF MEMECYLAENE NANOEMULSION
}

\author{
N.D. Rekha ${ }^{1^{*}}$, Dattatri K. Nagesha ${ }^{2}$, P. H. Rajasree ${ }^{3}$, N. Shruthi ${ }^{3}$ \\ ${ }^{1}$ Department of Studies in Biotechnology, JSS College of Arts, Commerce and Science, Ooty road, Mysore 570025, Karnataka, \\ India. \\ ${ }^{2}$ Bharath Hospital \& Institute of Oncology, Mysore 570017, Karnataka, India. \\ ${ }^{3}$ Department of Pharmaceutics, JSS College of Pharmacy, JSS Academy of Higher Education and Research, S.S. Nagar, Mysore \\ 570015, Karnataka, India.
}

\begin{abstract}
The present study was undertaken to formulate and evaluate the anti-inflammatory, anti-oxidant and anti-angiogenic activities of nanoemulsion of Memecylaene. Memecylaene was isolated from the leaves of Memecylon malabaricum by using various chromatographic methods. An oil-in-water $(\mathrm{O} / \mathrm{W})$ nanoemulsion of Memecylaene was formulated by sonication method using sunflower oil (oil phase), Tween 80 (Surfactant) and Ethanol (co-surfactant). The prepared nanoemulsion was characterized for its droplet size, poly dispersity index and zeta potential. Stability studies were performed and the nanoemulsions were subjected to different biological activities. The formulated nanoemulsion had a particle size range of $52.02 \mathrm{~nm}$ to $59.47 \mathrm{~nm}$ and zeta potential of $1.27 \mathrm{mV}$. The enhanced activity of Memecylaene, encapsulated in $\mathrm{O} / \mathrm{W}$ emulsions is evidenced by the inhibition of phospholipase (PLA2) enzyme and $\mathrm{H}^{+}, \mathrm{K}^{+}$-ATPase and thus showing anti-inflammatory and anti-secretagogues effects. The in vitro anti-oxidant activity was evaluated by DPPH radical and Nitric oxide radical scavenging activity. Further, the inhibition of the growth of neo vessels formation in the in-vivo model system of chick chorioallantoic membrane (CAM) assay, which is angiogenesis dependent, was also observed. The above findings would help in understanding the putative potential of Memecylaene-loaded nanoemulsion as a therapeutic agent.
\end{abstract}

Keywords: Anti-angiogenesis, Anti-oxidant, Gastric $\left(\mathrm{H}^{+} \mathrm{K}^{+}\right)$, Memecylaene, Nanoemulsion, Phospholipase A2 (PLA2).

Article Info: Received 15 July, 2018; Review Completed 11 Sep 2018; Accepted 12 Sep 2018; Available online 15 Oct 2018

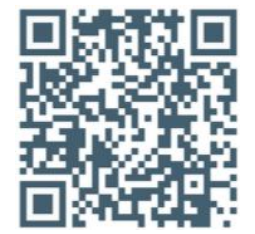

Cite this article as:

Rekha ND, Nagesha DK, Rajasree PH, Shruthi N, Formulation, characterization and evaluation of antiinflammatory and anti-angiogenic activities of memecylaene nanoemulsion , Journal of Drug Delivery and Therapeutics. 2018; 8(5-s):126-131 DOI: http://dx.doi.org/10.22270/jddt.v8i5-s.1915

N.D. Rekha, Department of Studies in Biotechnology, JSS College of Arts, Commerce and Science, Ooty road, Mysore 570025, Karnataka, India.

\section{INTRODUCTION}

Memecylon malabaricum is a medicinal plant indigenous to the Western Ghats of India. It is a potent plant material containing a number of bioactive compounds like steroids, triterpenes, flavonoids, saponins, tannins and resins. The leaves are being used as a traditional remedy to cure skin diseases, several stomach disorders, chicken pox, polyuria, menorrhagia and herpes ${ }^{1}$. Memecylaene,4,9,14,19-Tetramethyl1,6,11,16-tetraoxacycloeicosa-3,8,13,19-tetraene plays a promising role as an anti-angiogenic, anti-proliferative, pro-apoptotic, anti-oxidant and anti-inflammatory molecule in vivo and ex vivo experiments ${ }^{2}$. The molecule showed a unique structure simulating crown ethers with promising biological potency. Memecylaene, a highly lipophilic compound, exhibits dissolution related problem and low absorption; therefore, the efficacy may be greatly reduced. Hence, a prospective drug delivery system is essential to enhance the therapeutic index of Memecylaene, by improving its solubilisation property and modifying their 
pharmacokinetic profiles. Hence, a unique formulation to alter its physicochemical characteristics is required. The molecule being soluble in sunflower oil to a greater extent, a simple nanoemulsion (NE) system was formulated with no input of high-energy methods, which makes the molecule readily available for transdermal injection.

The design of effective formulations of NE for drugs has always been a major challenge due to severely limited drug efficacy can be of instability or its hydrophobicity. Using nanoparticles (NPs) as drug delivery systems is one of the most promising technologies that are being applied to improve the solubility and bioavailability of hydrophobic drugs. The transport properties of the drug would be influenced by the nanosized droplets that lead to an enormous increase in interfacial areas that are associated with NPs. NEs are unique due to the presence of compartmentalized hydrophobic domains in which both non-polar and polar compounds could be incorporated $^{3,4}$. There are several reports on plant-based essential oil-derived NE system that have prospective applications in pharmaceuticals ${ }^{5}$. In our current study, a biologically acceptable oil-in-water NE system as molecule delivery vehicle for Memecylaene to improve the efficacy and stability of the drug without the input of high energy methods was optimized. This system is expected to enable easy transport through the smallest capillary vessels without any discrimination by the host defence mechanism and thereby, readily absorbed by the organs.

\section{MATERIALS AND METHOD}

\section{Materials}

Memecylon malabaricum leaves, Silica gel for column chromatography, Sunflower oil, Tween 80, ethanol, Phosphate Buffer Saline, Omeprazole (Ome), Russell viper venom, Kreb's ringer buffer, 2mM HEPES-Tris, Sucrose-EDTA buffer, fertilized eggs, Butylated hydroxyl toluene (BHT), 1, 1-diphenyl 2-picrylhydrazyl (DPPH).

\section{Methods}

\section{Isolation of Memecylaene}

The leaves of Memecylon malabaricum collected from the Western Ghats, Karnataka state, India and identified and authenticated by the taxonomist. They were shade dried and coarsely ground. The ground leaves were loaded onto the Soxhlet for extraction, using hexane as the solvent system. The extract was filtered and loaded onto the column packed with silica gel (100-200 mesh) in chloroform and eluted in chloroform. The fraction collected was precipitated using methanol and filtered. Memecylaene was purified from the residue using thin layer chromatography. Thus obtained Memecylaene was used for the preparation of nanoemulsion.

\section{Preparation of nanoemulsion}

NE was prepared by the sonication method. $0.1 \mathrm{~g}$ of Memecylaene was dissolved in $0.5 \mathrm{mg}$ of sunflower oil and was added to $2 \mathrm{ml}$ of $S_{\text {mix }}$ (1:1.5 ratio of Tween 80: Ethanol) in a beaker placed on a magnetic stirrer. Water was simultaneously added drop wise and was left to form a uniform mixture on the magnetic stirrer for a known interval of time. The whole mixture was made to undergo probe sonication for a known interval of time and speed. The formulation table of the prepared NE is given in Table 1.

\section{Stability studies of the nanoemulsion}

Four cycles of the heating-cooling cycle between refrigerator temperature $\left(4^{\circ} \mathrm{C}\right)$ and $45^{\circ} \mathrm{C}$ was conducted, with the storage at each temperature for not less than 48 hours; and the formulation was examined for stability at all these temperatures. The formulation was also centrifuged at 3,500 rpm for 30 minutes and examined for phase separation. The formulation was subjected to four freeze-thaw cycles between $-21^{\circ} \mathrm{C}$ and $+25^{\circ} \mathrm{C}$ and observed for phase separation ${ }^{6}$.

\section{Characterization of the nanoemulsion}

\section{Particle size analysis, polydispersity index (PDI) and} measurement of surface charge

NE formulations were analyzed for particle size and size distribution by Malvern zetasizer. Particle size, size distribution and zeta potential were measured by dynamic light scattering (DLS). Initially, before filtration, higher peaks were found and upon filtration, lower peaks were observed. Zeta potential $(\zeta)$ measurements of the NE formulations were performed using Malvern zetasizer.

\section{Visual characterization:}

The NE was investigated for the presence of structures visible to the eye as well as for its texture.

\section{Assay of phospholipase A2 (PLA2) by indirect hemolytic method}

PLA2 activity was carried out by using an indirect hemolytic method of Boman HG and Kaletta ${ }^{8}$.Briefly, the packed human erythrocytes, egg yolk and phosphate buffered saline (1:1:8 V/V) were mixed accordingly. $1 \mathrm{ml}$ of this suspension was incubated separately with 60 $\mu \mathrm{g}$ of $V$. russelli venom for $10 \mathrm{~min}$ at $37^{\circ} \mathrm{C}$; the reaction was stopped by adding $10 \mathrm{ml}$ of ice-cold phosphate buffer saline and centrifuged at $4^{\circ} \mathrm{C}$ for $10 \mathrm{~min}$ at $800 \times g$. The amount of hemoglobin released into the supernatant was measured at $540 \mathrm{~nm}$. The assay was also carried out in the presence of various concentrations 2, 4,6, 8 and $10 \mu \mathrm{g}$ of NE. Lysis of erythrocytes by adding $9 \mathrm{ml}$ of distilled water to the control reaction mixture was taken as $100 \%{ }^{9}$.

\section{Gastric $\mathbf{H}^{+} / \mathrm{K}^{+}$-ATPase activity}

ATPase activity was determined as described by Im et al. ${ }^{10}$. Basal $\mathrm{Mg}^{2+}$ dependent ATPase activity was measured in $1.0 \mathrm{ml}$ of the reaction medium consisting of $2 \mathrm{mmol} / \mathrm{l} \mathrm{ATP}$ and $50 \mathrm{mmol} / \mathrm{l}$ Tris- $\mathrm{HCl}$ buffer ( $\mathrm{pH} 7.5$ ), $\mathrm{K}^{+}$-stimulated and $\mathrm{HCO}_{3}{ }^{-}$stimulated. ATPase activity was defined as the activity in the basal medium. The ATPase reaction was started by the addition of the substrate (ATP), carried out at $37^{\circ} \mathrm{C}$ for 15 minutes and stopped with $1.0 \mathrm{ml}$ ice-cold $20 \%$ Tri Chloro Acetic acid (TCA), liberated inorganic phosphate from ATP was estimated by Tsai method ${ }^{11}$. 
All experiments were repeated in triplicates in three independent sets. The assay was also carried out in the presence of various concentrations 2,8 and $10 \mu \mathrm{g}$ of NE. Percent inhibition was calculated by the comparison of the inhibition by NE with that of the drug Omeprazole (Ome) taken as a standard compound. The concentration of test compound causing 50\% inhibition (IC50, $\mu \mathrm{g} / \mathrm{ml}$ ) was calculated from the concentration-inhibition response curve.

\section{Anti-oxidant studies}

\section{DPPH radical scavenging assay}

DPPH radical scavenging activity was carried out as previously reported by Lingappa Mallesha et al. ${ }^{12}$. Briefly, different aliquots of NE; 2, 4, 6 and $8 \mu \mathrm{g}$ was mixed with $1 \mathrm{ml}$ of DPPH solution $(0.1 \mathrm{mM}$ in $95 \%$ ethanol) under vigorous shaking. The mixture was allowed to stand for 20 minutes at room temperature and following this, absorbance was measured at $517 \mathrm{~nm}$ with a UV-VIS spectrophotometer (HITACHI, U-2900). Radical scavenging potential was expressed as an IC50 value, i.e., the concentration at which DPPH radicals were scavenged up to $50 \%$. As a positive control for DPPH radical scavenging assay, BHT was used.

\section{Nitric oxide radical scavenging activity}

Griess reaction was used to measure the nitric oxide generated from sodium nitroprusside. It has been shown that nitric oxide is generated when sodium nitroprusside is introduced in phosphate buffer at physiological $\mathrm{pH}^{13}$. Griess reagent is used to estimate the nitrate ion produced by the reaction between nitric oxide and oxygen. The nitric oxide radical scavenging activity was carried out according to Lingappa Mallesha et al. ${ }^{12}$ with slight modifications. Briefly, reduced production of nitric oxide can be seen when the nitric oxide scavengers compete with oxygen. Different aliquots of $\mathrm{NE}$; 3,6,9,12 and $15 \mu \mathrm{g}$ was taken and mixed with sodium nitroprusside $(5 \mathrm{mM})$ in phosphate buffered saline and this mixture was incubated at $25^{\circ} \mathrm{C}$ for 3 hours. The absorbance was read against BHT that was treated the same way with the Griess reagent at $546 \mathrm{~nm}$ for the color formed during the diazotization of sulphanilamide with nitrite and coupling subsequently with naphylethylenediamine.

\section{Angioinhibitory effect by Shell-less chorioallantoic membrane (CAM) assay}

Shell-less chorioallantoic membrane assay is an angiogenic assay used for the validation of angioinhibitory activity of any given compound. The CAM assay, to note the anti-angiogenic activity was performed using the NE of Memecylaene. The antiangiogenic effect was studied according to the method reported by Bushra Begum et al. ${ }^{14}$ with slight modifications. Briefly, surface sterilization of fertilized hen's eggs was done using 70\% alcohol. Fan assisted humidified incubator at $37^{\circ} \mathrm{C}$ was used to incubate the eggs. Within a laminar air flow, 4 day old eggs were cracked out into thin films of the hammock and these eggs were further incubated. Proliferating blood vessels were seen from the center of the eggs within the hammock on the $5^{\text {th }}$ day; later, over these proliferating blood vessels, the filter paper discs loaded with $5 \mu \mathrm{g}$ of Memecylaene NE were placed and the eggs were incubated again. Results for the anti-angiogenic effect of the molecule were observed after 24 hours of incubation.

\section{RESULTS AND DISCUSSION}

Table 1: Formulation chart

\begin{tabular}{|l|l|l|l|l|l|}
\hline Formulation & Oil & $\begin{array}{l}\text { Surfactant mix }\left(\mathbf{S}_{\text {mix }}\right) \\
\text { [Tween 80+Ethanol] }\end{array}$ & Water & $\begin{array}{l}\text { Surfactant: Co-surfactant } \\
\text { (Tween 80: Ethanol) }\end{array}$ & Oil: $\mathbf{S}_{\text {mix }}$ \\
\hline Memecylaene NE & $0.5 \mathrm{mg}$ & $2 \mathrm{ml}$ & $7.5 \mathrm{ml}$ & $1: 1.5$ & $1: 4$ \\
\hline
\end{tabular}

\section{Stability studies of the nanoemulsion}

After the heating-cooling cycle, centrifugation test and freeze-thaw cycle, no phase separation was seen in the prepared NE. There were no sediments and hence the NE was found to be stable (Fig. 1).

\section{Characterization of the nanoemulsion}

Particle size analysis, polydispersity index (PDI) and measurement of surface charge

Upon scanning, the size of the blank NE was found to be in the range of $11.55 \mathrm{~nm}$ to $11.65 \mathrm{~nm}$; and that of the drug-loaded NE was found to be in the range of 52.02 $\mathrm{nm}$ to $59.47 \mathrm{~nm}$. The PDI of the blank NE was found to be 0.400 and that of the drug-loaded NE was found to be 0.990 . Zeta potential of the blank NE was found to be $1.23 \mathrm{mV}$ and that of the drug-loaded $\mathrm{NE}$ was found to be $-1.27 \mathrm{mV}$.

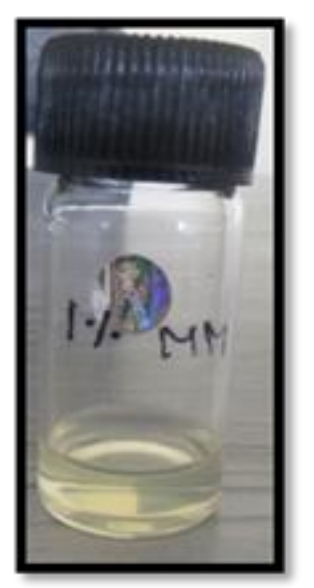

Figure 1: The photograph of the Stable Memecylaene NE after stability studies 


\section{Visual characterization}

The formulation had a visually appealing, homogeneous appearance which was retained over the observation period of two months. The formulated NE had a transparent pale yellow appearance, which in turn fulfils its criteria of being an NE.
Assay of phospholipase A2 by indirect hemolytic method

Inhibition of Russell viper venom PLA2by NE was dose-dependent with an IC50 value of $8.92 \mu \mathrm{g} / \mathrm{ml}$ (Fig.2A). The percentage of PLA2 enzyme that causes inflammation inhibition increased with the increased concentration of the NE.
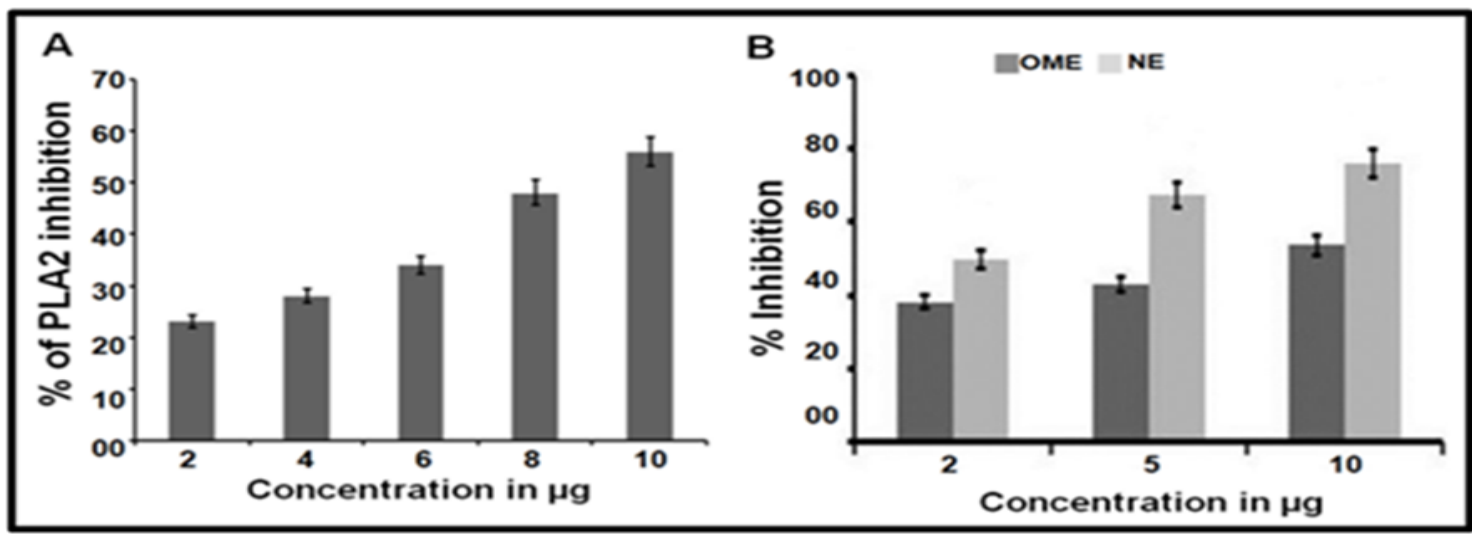

Fig. 2: PLA2 inhibition and gastric. (A)Inhibition of PLA2 of Russell viper venom by NE of Mermecylaene. (B)Inhibition of gastric $(\mathrm{H}+\mathrm{K}+)$ ATPase inhibition by NE of Memecylaene.

\section{Gastric $\left(\mathbf{H}^{+} \mathbf{K}^{+}\right)$ATPase inhibition}

The enzyme was collected from the fundic region of the sheep and was stored in the sucrose EDTA buffer. ATPase activity in various gastric membranes was determined. The liberated inorganic phosphate from ATP was estimated by Tsai method ${ }^{11}$. The NE was compared with the standard drug Omeprazole, and the $\mathrm{NE}$ inhibited $\left(\mathrm{H}^{+}-\mathrm{K}^{+}\right)$ATPase to a greater extent compared with the standard drug. The inhibition of ATPase was dose-dependent (Fig.2B). The NE showed an IC50 value of $6.57 \mu \mathrm{g} / \mathrm{ml}$ compared to that of the reference drug omeprazole with an IC50value of $9.32 \mu \mathrm{g} / \mathrm{ml}$.

\section{Anti-oxidant studies}

\section{DPPH radical scavenging assay}

One of the characteristic properties of natural antioxidants is their ability to scavenge free radicals. DPPH scavenging assay is used to quantify protonradical scavenging action of antioxidant. DPPH has absorbance maxima of $517 \mathrm{~nm}$. In the presence of an antioxidant, the absorbance maxima decrease as scavenging of proton-radical take place ${ }^{15}$. Free radical scavenging potential is demonstrated by the ability of the DPPH molecule to donate hydrogen. NE shows DPPH radical scavenging activity due to its hydrogen donating capacity. In this work, DPPH radical scavenging activity of Memecylaene loaded NE had an IC50 value of $5.13 \mu \mathrm{g} / \mathrm{ml}$ and comparable with the IC50 value of $4.36 \mu \mathrm{g} / \mathrm{ml}$ for BHT (Fig.3A). DPPH antioxidant activity of the $\mathrm{NE}$ was compared to the reference compound BHT and the NE showed an increased radical scavenging activity as the concentration was increased.

\section{Nitric oxide radical scavenging activity}

NE's of both Memecylaene and BHT showed a significant nitric oxide radical scavenging activity. Sodium nitroprusside generated nitric oxide at the physiological $\mathrm{pH}$ was inhibited by NE of Memecylaene with an IC50 value of $3.6 \mu \mathrm{g} / \mathrm{ml}$ and BHT with an IC50 value of $3.84 \mu \mathrm{g} / \mathrm{ml}$. The result reveals that the NE and $\mathrm{BHT}$ are almost similar in their potency in scavenging the nitric oxide radicals (Fig.3B).

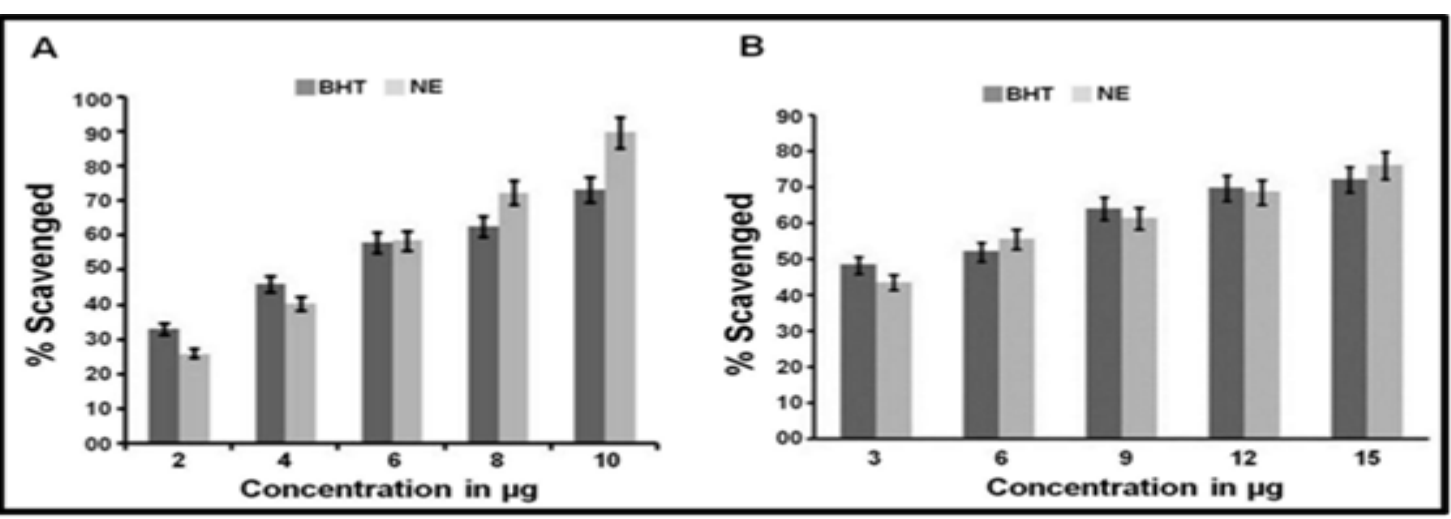

Fig. 3: Anti-oxidantstudies (A) DPPH antioxidant activity of NE of Memecylaene. (B) Nitric oxide radical scavenging activity of $\mathrm{NE}$ of Memecylaene. 


\section{Angio-inhibitory effect by Shell-less chorioallantoic membrane (CAM) assay}

The angio-inhibitory activity of the NE is as shown in the (Fig.4A); exhibited significant positive results in the shell-less CAM assay model of developing embryos. The data shown represent the results using a minimum of six eggs in each group. The investigation of antiangiogenic activity of NE of Memecylaene (Fig.4B) showed a significant reduction of proliferation of capillaries around the zone of application of the discs loaded with the $5 \mu \mathrm{g}$ of NE. These results indicate that the NE forms a potent anti-angiogenic agent in vivo.

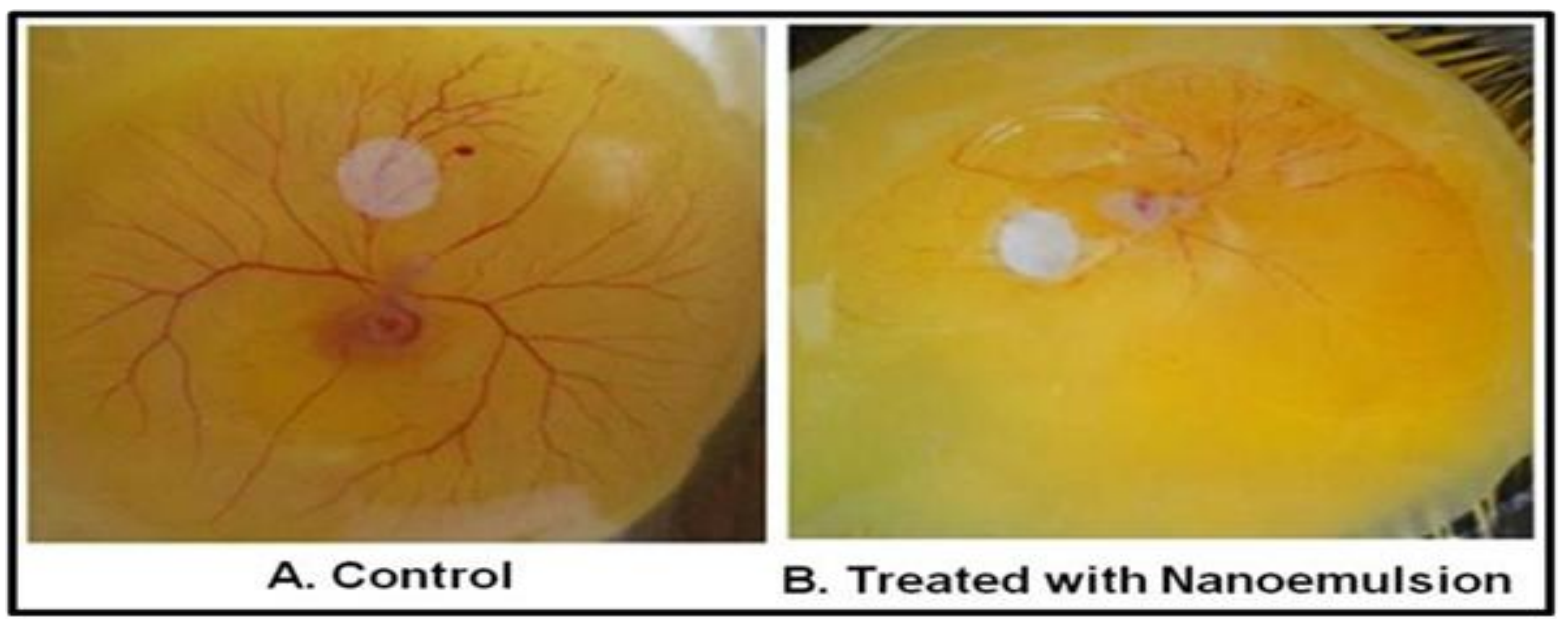

Fig. 4: Suppression of in vivo angiogenesis by NE of Memecylaene. (A) Control. (B) Treated with $5 \mu \mathrm{g}$ of $\mathrm{NE}$ in shell-less CAM assay model.

Memecylon malabaricum is a potent plant material containing a number of bioactive compounds like steroids, triterpenes, flavonoids, saponins, tannins and resins. The methanolic extract of the plant is reported to have anti-microbial activity ${ }^{16}$ and anti-diabetic activity ${ }^{17}$. According to the literature, the solubility of Memecylaene molecule was difficult due to its hydrophobic nature and therefore, an effort was made to prepare an NE to increase its solubility and to assess its biological activities.

The results of all these studies suggest that NE is a promising novel formulation that can enhance the solubility of Memecylaene, comprising of Memecylaene and sunflower oil in the oil phase, Tween 80 and ethanol in the water phase. Thus, the nano droplets comprised of the hydrophobic molecule 'Memecylaene', surrounded by surfactant and co-surfactant $\left(\mathrm{S}_{\mathrm{mix}}\right)$.

\section{CONCLUSION}

NE was prepared to increase the solubility of Memecylaene, a hydrophobic molecule which was isolated from Memecylon malabaricum was found to be a potent biologically active molecule which can be used as a readily available drug for transdermal delivery. Through proper selection of all the critical components required for the synthesis of NE, stable drug-loaded NE was prepared.

$\mathrm{NE}$, to date, have been shown to be able to protect labile drugs, control its release, increase the bioavailability, reduce patient variability and increase drug solubility. The results of these studies indicate the potential role of $\mathrm{O} / \mathrm{W}$ type of NE for enhancing the solubility of the hydrophobic molecule Memecylaene. The reduction of pro-inflammatory biomarkers and an increase in antioxidant activity with inhibition of PLA2 shown by Memecylaene is a proof for its anti-inflammatory activity. We are reporting in our study that NE of Memecylaene forms an excellent biocompatible drug delivery system comprised of sunflower oil, Tween 80 and water for the solubilisation of poorly water-soluble Memecylaene. The Memecylaene was found to be highly solubilized in sunflower oil ranging about $10 \mathrm{mg} / \mathrm{ml}$. Further, when incorporated into the oil core of the NE system, the drug degradation factor is greatly reduced and it maintained a good thermodynamic stability with better drug-loading capacity. Moreover, the particle size reduction of the drug to nanometres range would significantly improve the dissolution rate and thereby improve the bioavailability of the molecule in in-vivo after administration. Thus, the therapeutic efficacy of the drug would be enhanced to meet the patient's need. Also, the development of NE formulation of Memecylaene with optical clarity and low-viscosity involving no high-energy methods would be of interest to pharmaceutical scientists.

\section{CONFLICT OF INTEREST}

The authors confirm that this article content has no conflict of interest.

\section{ACKNOWLEDGEMENTS}

The isolation of the plant molecule, Memecylaene, was done by Dr. N. D. Rekha, Dr. Dattatri K. Nagesha guided the whole process of converting the molecule into an NE. P. H. Rajasree optimized the NE and continued to its characterization and analysis. N. Shruthi helped with the reckoning. We sincerely thank JSS College of Pharmacy, Mysore, JSS Academy of Higher Education and Research and JSS Mahavidyapeeta for providing research facilities to carry out this work. This research did not receive any specific grant from funding agencies in the public, commercial, or not-for-profit sector. 


\section{REFERENCES}

1. Bharathi TR, Sampath Kumar KK, Prakash HS. memecylon species: a review of traditional information and taxonomic description. International Journal of Pharmacy and Pharmaceutical Sciences, 2016; 8(6):27-34.

2. Rekha ND, Gowda TV, Aradhya SM, Suresha RN, Jayashree K. Anti-inflammatory properties of Memecylaene: A novel compound isolated from Memecylaene Malabaricum. Research Journal of Pharmaceutical, Biological and Chemical Sciences, 2014; 5:1645-1654.

3. Shafiq S, Shakeel F, Talegaonkar S, Ahmad FJ, Khar RK, Ali M. Development and bioavailability assessment of Ramipril nanoemulsion formulation. European Journal of Pharmaceutics and Biopharmaceutics, 2007; 66:227-243.

4. Nagarajan R, Ruckenestein E. Molecular theory of microemulsions. Langmuir, 2000; 16:6400-6415.

5. Joyce NM, Nagarajan R. Recent research trends in fabrication and applications of plant essential oil based nanoemulsions Journal of Nanomedicine and Nanotechnology, 2017; 8:1-10.

6. Srilatha R, Aparna C, Srinivas P, Sadanandam M. Formulation, evaluation and characterization of Glipizide nanoemulsion. Asian Journal of Pharmaceutical and Clinical Research, 2013; 6:66-71.

7. Rajasree PH, Willi P, Chandra P S, Riaz A O, Umme H, Atul S. Eudragit encapsulated cationic poly(lactic-co-glycolicacid) nanoparticles in targeted delivery of capecitabine for augmented colon carcinoma therapy. Journal of Drug Delivery Science and Technology. 2018; 46:302-311.

8. Boman HG, Kaletta U. Chromatography of rattlesnake venom: A separation of three phosphodiesterases. Biochimica et Biophysica Acta, 1957; 24:619-631.

9. Mohamed R, Dharmappa KK, Tarannum S, Jameel NM, Kannum SA, Ashrafulla HS et al. Chemical modification of ascorbic acid and evaluation of its lipophilic derivatives as inhibitors of secretory phospholipase A2 with antiinflammatory activity. Molecular and Cellular Biochemistry, 2010; 345:69-76.

10. Im WB, Sih JC, Blakeman DP, Megrath JP. Omeprazole, a specific inhibitor of Gastric $(\mathrm{H}+, \mathrm{K}+)$ ATP ase is a $\mathrm{H}+$ activated oxidizing agent of sulfhydryl groups, The Journal of Biological Chemistry.1985; 260:4591-4597.

11. Tsai CM, Chen KY, Canellakis ES. Isolation and characterization of the plasma membrane of 1-1210 cells. Iodination as a marker for the plasma membrane. Biochimica et Biophvsica Acta(BBA)-Biomembranes, 1975; 401:196-212.

12. Mallesha L, Kikkeri PH, Kikkeri NM, Rekha ND. In vitro anti-oxidant activity of 1-[5-(4-Methoxy-phenyl)- [1,3,4] oxadiazol-2-yl] piperazine derivatives. Canadian Chemical Transactions, 2014; 2:518-525.

13. Marcocci L, Packer L, Droy LMT, Sekaki A, Gardes AM. The anti-oxidant action of Ginko biloba extracts EGb761. Methods in Enzymology, 1994; 234:462-475.

14. Bushra BA, Rekha ND, Vasantha Kumar BC, Lakshmi RV, Khanum SA. Synthesis, characterization, biological and catalytic applications of transition metal complexes derived from Schiff base. Bioorganic and Medicinal Chemistry Letters, 2014; 24:3559-3564.

15. Yamaguchi T, Takamura H, Matoba T, Terao J. HPLC method for evaluation of the free radical scavenging activity of foods by using 1,1-diphenyl-2-picrylhydrazyl. Bioscience. Biotechnology and Biochemistry, 1998; 62:1201-1204.

16. Hullatti KK, Ravi VR. Anti-microbial activity of Memecylon Malabaricum leaves. Fitoterapia, 2004; 75:409-411.

17. Ramaiah M, Srikantha RK, Rao BG. Anti-diabetic activity of methanolic extract of Memecylon malabaricum (Melastomataceae) leaves. International Journal of Phytopharmcy, 2012; 10:160-166. 